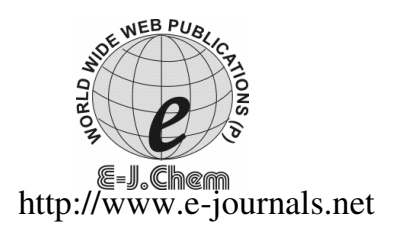

ISSN: 0973-4945; CODEN ECJHAO
E-Journal of Chemistry
2012, 9(1), 203-210

\title{
Kinetics and Mechanism of Oxidation of $t$-Butylbenzylamine by Diperiodatoargentate(III) in Aqueous Alkali
}

\author{
MAHANTESH A. ANGADI and SURESH M. TUWAR* \\ Department of Chemistry \\ Karnatak Science College, Dharwad-580 001, India \\ sm.tuwar@gmail.com
}

Received 29 June 2011; Accepted 27 August 2011

\begin{abstract}
Butylbenzylamine ( $t$-BA) is used as a free base in the synthesis of salbutamol drug. Its mechanism of oxidation was proposed from kinetic studies. The kinetics of oxidation of $t$-butylbenzylamine by diperiodatoargentate(III) (DPA) was studied spectrophotometrically by monitoring decrease in absorbance of DPA. The reaction was found to be first order each in [DPA] and $[t-\mathrm{BA}]$. The effect of alkali concentration in a wide range on rate of reaction was studied. The rate of reaction was found to be increased with increase in $\left[\mathrm{OH}^{-}\right]$in the lower range of $\left[\mathrm{OH}^{-}\right]$, decreasing effect in the middle range and at higher range again increasing effect on rate of reaction was observed. The added periodate retarded the rate of reaction. The polymerization test revealed that oxidation was occurred with the intervention free radical. A suitable mechanism was proposed for a middle range of $\left[\mathrm{OH}^{-}\right]$. The active species of silver(III) periodate for all the three different stages of $\left[\mathrm{OH}^{-}\right]$are assayed. Rate law was derived and verified. The oxidative product of $t$-BA was characterized by LC-ESI-MS spectra.
\end{abstract}

Keywords: Diperiodatoargentate(III), $t$-Butylbenzylamine, Oxidation, Kinetics, Periodate

\section{Introduction}

$t$-Butylbenzylamine ( $t$-BA) is a precursor in the synthesis of salbutamol, which is used as anti-asthmatic drug. It is an active intermediate for most of other asthmatic drugs also 1 . Although $t$-BA is active free base and essential component of the salbutamol drug, it causes respiratory tract irritation and may lead to pulmonary edema. Inhalation of $t$-BA at high concentration may cause CNS (central nervous system) depression and asphyxiation. Hence, the trace amount of $t$-BA as impurity in salbutamol or general asthmatic drugs may lead all such toxicological effects ${ }^{2}$. The synonym of $t$-BA is $N$-(1,1-dimethylethyl)-benzenemethanamine. The toxicological properties of the substance have not yet fully investigated. 
The oxidative property of this may help to understand its toxic effect. Hence, in the present study we report the oxidation of t-butylbenzylamine by silver(III) periodate in basic media.

Silver(III) is highly stable ${ }^{3}$ in presence of chelates like periodate, tellurate and ethylenebis(biguanide). Silver(III) tellurate complex has been used as an analytical reagent for the determination of carbohydrates and some inorganic ions ${ }^{4}$. However, its unstability has lost the interest for its use as analytical reagent. Nevertheless, the other forms of silver(III) like silver(III) periodate and silver(III) ethylenebis(biguanide) play an important role in the analytical chemistry $y^{5,6}$. There stability is exploited in the kinetic studies in which they are used as oxidizing agents in highly alkaline medium ${ }^{7,8}$. The literature reveals that very small number of oxidizing agents is available in such media. Amongst these, silver(III) periodate is a simple complex which can easily be prepared. Apart from this the silver(III) periodate is existed in various reactive forms depending upon the concentration of $\mathrm{OH}^{-}$used. In the present investigation we have used $\left[\mathrm{OH}^{-}\right]$in a wide range. The active form of silver(III) periodate in different stages of $\left[\mathrm{OH}^{-}\right]$have been arrived. The literature reveals that no attempts have been made for the use of silver(III) periodate complex as an oxidant to understand the oxidative property of the intermediates like t-butylbenzylamine which is used in the synthesis of salbutamol. Hence, the title reaction is undertaken for the study of oxidation of $t$-butylbenzylamine and to know the various forms of silver(III) periodate in a wide range of alkali concentration.

\section{Experimental}

The used chemicals $\mathrm{KOH}, \mathrm{KIO}_{4}, \mathrm{KIO}_{3}, \mathrm{~K}_{2} \mathrm{~S}_{2} \mathrm{O}_{8}, \mathrm{NaOH}, \mathrm{KNO}_{3}$ and acrylonitrile were of analytical grade. The reaction solutions were prepared in millipore water free from dissolved oxygen and carbon dioxide. The acrylonitrile and $\mathrm{K}_{2} \mathrm{~S}_{2} \mathrm{O}_{8}$ were purified by distillation and re-crystallization respectively to remove any traces of impurities.

The main reagents $t$-butylbenzylamine hydrobromide ${ }^{9}$ and silver(III) periodate complex ${ }^{10}$ were synthesized and standardized by reported methods. The silver(III) periodate complex was characterized from its UV-Vis spectrum exhibited three peaks at 214,255 and $362 \mathrm{~nm}$. These spectral features were identical to those reported earlier for $\mathrm{DPA}^{10}$. The compound prepared above was analyzed ${ }^{11}$ for silver and periodate by acidifying a solution of the material with $\mathrm{HCl}$, recovering and weighing the $\mathrm{AgCl}$ for $\mathrm{Ag}$ and titrating the iodine liberated when excess of KI was added to the filtrate for $\mathrm{IO}_{4}^{-}$.

The stock solution of DPA was prepared by dissolving the required quantity of above silver(III) periodate complex in millipore water which also contained $1.0 \times 10^{-4} \mathrm{~mol} \mathrm{dm}^{-3}$ of $\mathrm{KIO}_{4}$ and $0.05 \mathrm{~mol} \mathrm{dm}{ }^{-3} \mathrm{KOH}$. Under this condition DPA was found to be stable for more than one month. Since the aqueous solution of DPA contained $\mathrm{IO}_{4}^{-}$, its reactivity with $t$-butylbenzylamine was tested and found that there was no significant interference due to $\mathrm{IO}_{4}{ }^{-}$under experimental condition.

Aqueous solution of $\mathrm{AgNO}_{3}$ was used to study the product effect, $\mathrm{Ag}(\mathrm{I})$. The aqueous solutions of $\mathrm{KNO}_{3}$ and $\mathrm{KOH}$ were used to maintain and vary the ionic strength and alkalinity respectively.

\section{Kinetics measurements}

The oxidation of $t$-butylbenzylamine by DPA was carried out under pseudo-first order condition where $\left[t\right.$-BA] $>[\mathrm{DPA}]$ at $30 \pm 1{ }^{0} \mathrm{C}$, unless otherwise specified. The reaction was initiated by mixing the required quantities of previously thermostated solution of $t$-BA and 
DPA, which also contained definite quantities of $\mathrm{KOH}, \mathrm{KNO}_{3}$ and $\mathrm{IO}_{4}{ }^{-}$to maintain the required alkalinity, ionic strength and periodate respectively. The total concentrations of periodate and $\mathrm{OH}^{-}$were calculated by considering the amount present initially in the DPA solution and that additionally added. The course of reaction was followed by measuring the decrease in absorbance of DPA in the reaction mixture in a $1 \mathrm{~cm}$ quartz cell of a thermostated compartment of Hitachi-U3310 spectrophotometer at its maximum absorbance, $\lambda_{\max }, 360 \mathrm{~nm}$ as a function of time. Earlier, it was verified that there is a negligible interference from other species present in the reaction mixture at this wavelength. The obedience of absorbance by DPA to Beer's law at the wavelength, $360 \mathrm{~nm}$ was verified earlier and the molar absorbance coefficient ' $\varepsilon$ ' was found to be $13900 \pm 100 \mathrm{dm}^{-3} \mathrm{~mol}^{-1} \mathrm{~cm}^{-1}$ at this wavelength.

The pseudo-first order rate constants, $\mathrm{k}_{\mathrm{obs}}$ were determined from the $\log$ (absorbance) versus time plots. The plots were linear upto $75 \%$ completion of reaction. The non-linearity above $75 \%$ was due to retarding effect of one of the products, silver(I) (discussed elsewhere). In view of the non-linearity of first order plots above $75 \%$ of reaction, the orders were also confirmed from initial rate method and found to be identical in both the methods. However, the orders for various species were determined from the slopes of plots of $\log \mathrm{k}_{\mathrm{obs}}$ versus respective concentration of species except for [DPA] in which non-variation of ' $\mathrm{k}_{\mathrm{obs}}$ ' was observed for its different concentrations as expected to the reaction condition. The results were reproducible within $\pm 5 \%$.

\section{Results and Discussion}

\section{Stoichiometry and product analysis}

Different sets of reaction mixtures containing varying ratios of DPA to t-butylbenzylamine in presence of constant amount of $\mathrm{OH}^{-}$and $\mathrm{KNO}_{3}$ were kept for $6 \mathrm{~h}$ in a closed vessel under an inert atmosphere. When [DPA] > [t-BA], the remaining [DPA] was estimated spectrophotometrically at $360 \mathrm{~nm}$. The results indicated that 1:1 ( $t$-BA: DPA) stoichiometry as shown in equation (1).



The oxidative product of t-butylbenzylamine was identified as 4-((t-butylamino) methyl)cyclohexa-2,5,dienone. It was analyzed by subjecting its aqueous solution to LC-ESI-MS analysis as follows: $20 \mu \mathrm{L}$ of acidified reaction mixture was injected. The mobile phase consists of $10 \mathrm{mM}$ ammonium acetate $\mathrm{pH} 3.0$ (eluent $\mathrm{A}$ ) and acetic acid (eluent B) at a flow rate of $1 \mathrm{cc} / \mathrm{min}$. Gradient elution was run to separate reaction products. The analysis indicated that the only a single product and then LC-ESI-MS showed a molecular ion $(\mathrm{m} / \mathrm{Z})$ peak at 177 (Figure 1) which was expected molecular mass of the product, 4-((t-butylamino) methyl)cyclohexa-2,5, dienone .

\section{Reaction orders}

Kinetics of oxidation of $t$-BA by alkaline DPA was studied in a wide range of $\left[\mathrm{OH}^{-}\right]$at constant [DPA], [t-BA], $\left[\mathrm{KIO}_{4}\right]$ and ionic strength at $30{ }^{\circ} \mathrm{C}$ (Table 1). It was observed that the rate of reaction was increased with increase in $\left[\mathrm{OH}^{-}\right]$from $5.0 \times 10^{-4}$ to $2.0 \times 10^{-3} \mathrm{~mol} \mathrm{dm}^{-3}$ 
and became optimum at $2.0 \times 10^{-3} \mathrm{~mol} \mathrm{dm} \mathrm{dm}^{-3}$; further increase in $\left[\mathrm{OH}^{-}\right]$from $2.0 \times 10^{-3}$ to $7.0 \times 10^{-3} \mathrm{~mol} \mathrm{dm}^{-3}$ the rate of reaction was decreased and thereafter increase of $\left[\mathrm{OH}^{-}\right]$from $8.0 \times 10^{-3}$ to $2.0 \times 10^{-2} \mathrm{~mol} \mathrm{dm}^{-3}$, the rate of reaction was again increased. The order in $\left[\mathrm{OH}^{-}\right]$in lower range was found to be unity, at the middle range -0.5 and at the higher range, +0.8 . Nevertheless, the kinetics of reaction was studied in the middle range of $\left[\mathrm{OH}^{-}\right]$and the orders for various species of the reaction were also determined in such range of $\left[\mathrm{OH}^{-}\right]$.

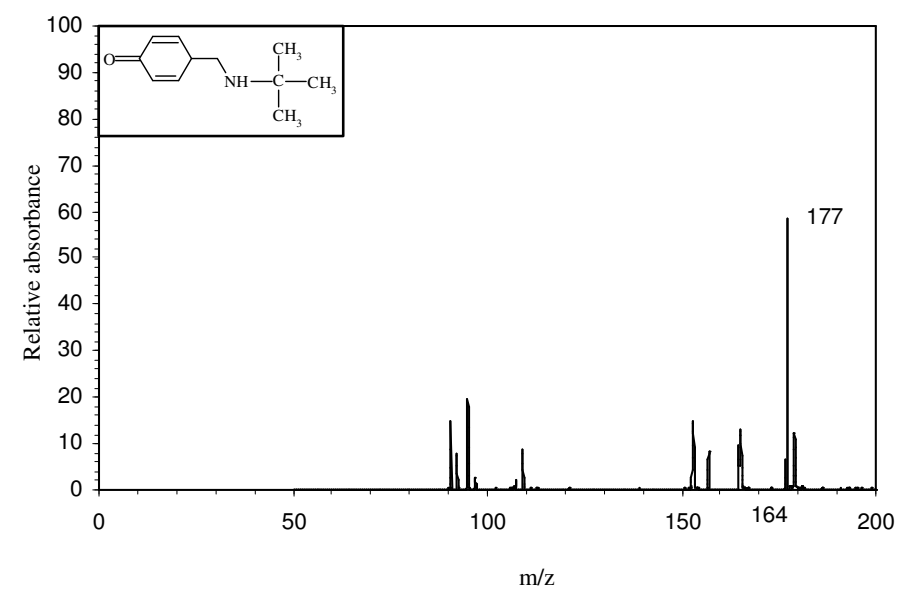

Figure 1. LC-ESI-MS spectra of oxidation of $t$-butylbenzylamine by diperiodatoargentate(III) in aqueous alkaline

At fixed $[t-\mathrm{BA}],\left[\mathrm{OH}^{-}\right],\left[\mathrm{IO}_{4}^{-}\right]$and ionic strength, the DPA concentration was varied in the range, $1.0 \times 10^{-5}$ to $1.0 \times 10^{-4} \mathrm{~mol} \mathrm{dm}^{-3}$. The non-variation in the pseudo-first order rate constants at various [DPA] indicates the order in [DPA] as unity (Table 1). This was also confirmed from the linearity of plots of $\log$ [DPA] versus time for about $75 \%$ completion of the reaction.

At $30{ }^{0} \mathrm{C}$, the substrate, $[t-\mathrm{BA}]$ was varied in the range, $3.0 \times 10^{-4}$ to $5.0 \times 10^{-3} \mathrm{~mol} \mathrm{dm}^{-3}$ keeping all other reactants concentrations constant. The $\mathrm{k}_{\mathrm{obs}}$ values were increased with increase in $[t-\mathrm{BA}]$ and its order was found to be unity (Table 1 ).

The dependency of rate of reaction on $\left[\mathrm{IO}_{4}{ }^{-}\right]$on the rate of reaction was studied by varying the $\left[\mathrm{IO}_{4}{ }^{-}\right]$from $5.0 \times 10^{-5}$ to $5.0 \times 10^{-4} \mathrm{~mol} \mathrm{dm}{ }^{-3}$ at constant concentrations of DPA, $t$-BA, alkali in the middle range and constant ionic strength. The rate constants were decreased with increase in $\left[\mathrm{IO}_{4}^{-}\right]$and order was calculated to be -0.8 (Table 1).

The influence of ionic strength (I) on reaction rate was studied by varying the $\left[\mathrm{KNO}_{3}\right]$ in the reaction medium. The ionic strength, I was varied from 0.05 to $0.5 \mathrm{~mol} \mathrm{dm}^{-3}$ at constant concentrations of DPA, $t$-BA, $\mathrm{IO}_{4}{ }^{-}$and alkali. It was observed that the rate of reaction is independent on ionic strength.

The dielectric constant (D) medium effect on rate of reaction was studied by varying the $t$-butyl alcohol/water percentage ( $\mathrm{v} / \mathrm{v})$. Since the ' $\mathrm{D}$ ' for various percentage compositions of $t$-butyl alcohol and water (v/v) was not available in literature, they were computed by using their ' $\mathrm{D}$ ' in pure state ${ }^{12}$. In the reaction, as ' $\mathrm{D}$ ' increases, the $\mathrm{k}_{\text {obs }}$ values were decreased. Earlier it was ascertained that there was no reaction between $t$-butyl alcohol and oxidant under experimental conditions used. The graph of $\log \mathrm{k}_{\mathrm{obs}}$ versus $1 / \mathrm{D}$ was found to be linear with positive slope. 
Table 1. Effect of variation of $\left[\mathrm{OH}^{-}\right],[\mathrm{DPA}],[t-\mathrm{BA}]$ and $\left[\mathrm{IO}_{4}^{-}\right]$on oxidation of $t$-butylbenzylamine by diperiodatoargentate(III) in aqueous alkaline medium at $30{ }^{\circ} \mathrm{C}$

\begin{tabular}{cccccc}
\hline $\begin{array}{c}{\left[\mathrm{OH}^{-}\right] \times 10^{2},} \\
\mathrm{~mol} \mathrm{dm}^{-3}\end{array}$ & $\begin{array}{c}{[\mathrm{DPA}] \times 10^{4},} \\
\mathrm{~mol} \mathrm{dm} \mathrm{dm}^{-3}\end{array}$ & $\begin{array}{c}{[t-\mathrm{BA}] \times 10^{3},} \\
\mathrm{~mol} \mathrm{dm}^{-3}\end{array}$ & $\begin{array}{c}{\left[\mathrm{IO}_{4}^{-}\right] \times 10^{4},} \\
\mathrm{~mol} \mathrm{dm}^{-3}\end{array}$ & \multicolumn{2}{c}{$\mathrm{k}_{\text {obs }} \times 10^{3}\left(\mathrm{~s}^{-1}\right)$} \\
\hline 0.05 & 5.0 & 1.0 & 1.0 & 0.79 & Calc. \\
0.10 & 5.0 & 1.0 & 1.0 & 1.74 & - \\
0.15 & 5.0 & 1.0 & 1.0 & 3.07 & - \\
0.20 & 5.0 & 1.0 & 1.0 & 3.66 & 3.52 \\
0.30 & 5.0 & 1.0 & 1.0 & 2.95 & 3.03 \\
0.40 & 5.0 & 1.0 & 1.0 & 2.61 & 2.66 \\
0.50 & 5.0 & 1.0 & 1.0 & 2.38 & 2.37 \\
0.60 & 5.0 & 1.0 & 1.0 & 2.12 & 2.14 \\
0.70 & 5.0 & 1.0 & 1.0 & 1.99 & 1.95 \\
0.80 & 5.0 & 1.0 & 1.0 & 2.63 & - \\
0.90 & 5.0 & 1.0 & 1.0 & 2.85 & - \\
1.00 & 5.0 & 1.0 & 1.0 & 3.23 & - \\
1.50 & 5.0 & 1.0 & 1.0 & 4.24 & - \\
2.00 & 5.0 & 1.0 & 1.0 & 5.96 & - \\
0.50 & 0.1 & 1.0 & 1.0 & 2.38 & - \\
0.50 & 0.2 & 1.0 & 1.0 & 2.39 & - \\
0.50 & 0.3 & 1.0 & 1.0 & 2.38 & - \\
0.50 & 0.5 & 1.0 & 1.0 & 2.38 & - \\
0.50 & 0.8 & 1.0 & 1.0 & 2.36 & - \\
0.50 & 1.0 & 1.0 & 1.0 & 2.38 & - \\
0.50 & 5.0 & 0.3 & 1.0 & 0.69 & 0.71 \\
0.50 & 5.0 & 0.5 & 1.0 & 1.15 & 1.19 \\
0.50 & 5.0 & 0.8 & 1.0 & 1.90 & 1.90 \\
0.50 & 5.0 & 1.0 & 1.0 & 2.38 & 2.37 \\
0.50 & 5.0 & 2.0 & 1.0 & 4.51 & 4.74 \\
0.50 & 5.0 & 3.0 & 1.0 & 6.25 & 7.12 \\
0.50 & 5.0 & 5.0 & 1.0 & 11.5 & 11.9 \\
0.50 & 5.0 & 1.0 & 0.5 & 3.84 & 3.82 \\
0.50 & 5.0 & 1.0 & 0.8 & 2.81 & 2.80 \\
0.50 & 5.0 & 1.0 & 1.0 & 2.38 & 2.37 \\
0.50 & 5.0 & 1.0 & 2.0 & 1.34 & 1.35 \\
0.50 & 5.0 & 1.0 & 3.0 & 0.87 & 0.94 \\
0.50 & 5.0 & 1.0 & 5.0 & 0.58 & 0.59 \\
\hline
\end{tabular}

$k_{\text {obs }}$ were calculated using $k=9.85 \mathrm{dm}^{3} \mathrm{~mol}^{-1} \mathrm{~s}^{-1}, K_{1}=2.0 \times 10^{-3} \mathrm{~mol} \mathrm{dm}^{-3}$ and $K_{2}=1.11 \times 10^{-4} \mathrm{~mol} \mathrm{dm}^{-3}$ in equation (6)

The experiment was also performed in presence of initially added product, $\operatorname{Ag}(\mathrm{I})$ in the concentration range, $1.0 \times 10^{-5}$ to $2.0 \times 10^{-4} \mathrm{~mol} \mathrm{dm}^{-3}$ when all other reactant concentrations were kept constant. The initially added $\mathrm{Ag}(\mathrm{I})$ had shown the retarding effect on rate of reaction from the $\mathrm{k}_{\mathrm{obs}}$ values $2.19 \times 10^{-3}$ to $0.99 \times 10^{-3}$ in the above range of $\left[\mathrm{Ag}^{+}\right]$with an order -0.3 .

The reaction mixture was mixed with a known quantity of acrylonitrile monomer and kept for $24 \mathrm{~h}$ under inert atmosphere. On dilution with methanol, a white precipitate of polymer was formed, indicating the intervention of free radicals in the reaction. The experiment of either DPA or $t$-butylbenzylamine with acrylonitrile alone did not induce polymerization under the similar condition as those induced with reaction mixture. Initially added acrylonitrile had also retarded the rate, indicating a free radical intervention ${ }^{13}$. 
The kinetics were also studied at $30,35,40,45$ and $50{ }^{\circ} \mathrm{C}$ at constant concentrations of reactants and other conditions being constant. The $\mathrm{k}_{\mathrm{obs}}$ at various temperatures were calculated as $2.38 \times 10^{-3}, 2.95 \times 10^{-3}, 3.79 \times 10^{-3}, 4.98 \times 10^{-3}$ and $6.18 \times 10^{-3} \mathrm{~mol} \mathrm{dm}^{-3}$. From the Arrhenius plot of log $\mathrm{k}_{\text {obs }}$ vs. $1 / \mathrm{T}$, the activation energy, Ea $\left(40.0 \pm 0.5 \mathrm{k} \mathrm{J} \mathrm{mol}^{-1}\right)$ was calculated and from this other activation parameters, $\Delta \mathrm{H}^{\#}\left(37.1 \pm 0.8 \mathrm{k} \mathrm{J} \mathrm{mol}^{-1}\right), \Delta \mathrm{S}^{\#}\left(-12.7 \pm 0.1 \mathrm{~J} \mathrm{~K}^{-1} \mathrm{~mol}^{-1}\right), \Delta \mathrm{G}^{\#}\left(42.0 \pm 1 \mathrm{k} \mathrm{J} \mathrm{mol}^{-1}\right)$ and $\log \mathrm{A}\left(4.3 \pm 0.1 \mathrm{dm}^{3} \mathrm{~mol}^{-1} \mathrm{~s}^{-1}\right)$ were computed

The water soluble silver(III) periodate exists ${ }^{14}$ in various forms depending upon the $\mathrm{pH}$ of the reaction medium. The structure of such complexes are mainly governed by the periodate species, as free periodate in aqueous solution shows various $\mathrm{pH}$ dependent equilibria ${ }^{10}$. In the $\mathrm{pH}$ range of 8-12, the predominant periodate species will be $\mathrm{H}_{2} \mathrm{IO}_{6}^{3-}$ and $\mathrm{H}_{3} \mathrm{IO}_{6}{ }^{2-}$. In alkaline medium periodate dimerizes and exists as $\mathrm{H}_{2} \mathrm{I}_{2} \mathrm{O}_{10}{ }^{4-}$ but it can be neglected in the present experimental conditions. Since the silver(III) periodate is a square planar with $\mathrm{dsp}^{2}$ geometry, the silver(III) periodate structure can be depicted as $\left[\mathrm{Ag}\left(\mathrm{H}_{2} \mathrm{IO}_{6}\right)_{2}\right]^{3-}$ or $\left[\mathrm{Ag}\left(\mathrm{H}_{3} \mathrm{IO}_{6}\right)_{2}\right]^{-}$. The degree of protonation of periodate is depending upon the $\left[\mathrm{OH}^{-}\right]$of the reaction medium.

In the present investigation, the reaction is studied in a wide range of $\left[\mathrm{OH}^{-}\right]$. In the lower range of $\left[\mathrm{OH}^{-}\right]$, the degree of protonation for periodate can be ascribed as $\mathrm{H}_{3} \mathrm{IO}_{6}{ }^{2-}$. In such a range of $\left[\mathrm{OH}^{-}\right]$i.e., $5.0 \times 10^{-4}$ to $2.0 \times 10^{-3} \mathrm{~mol} \mathrm{dm}{ }^{-3}$ the rate of reaction was found to be increased with increase in $\left[\mathrm{OH}^{-}\right]$which might be deprotonation of periodate as in equilibrium (2).

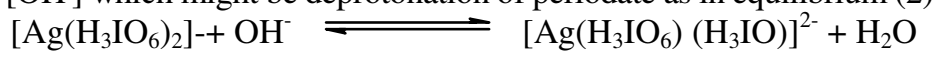

In the middle concentration range of $\mathrm{OH}^{-}$i.e., $2.0 \times 10^{-3}$ to $7.0 \times 10^{-3} \mathrm{~mol} \mathrm{dm}^{-3}$, this deprotonated diperiodatoargentate(III) loses the proton to give $\left[\mathrm{Ag}\left(\mathrm{H}_{2} \mathrm{IO}_{6}\right)_{2}\right]^{3-}$ as in equilibrium (3).

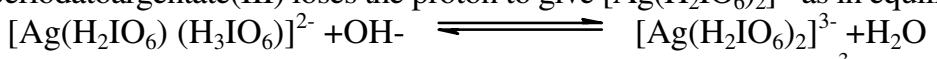

At higher range of concentration of $\mathrm{OH}^{-}$i.e., $7.0 \times 10^{-3}$ to $2.0 \times 10^{-2} \mathrm{~mol} \mathrm{dm}$, the deprotonated diperiodatoargentate(III) as in equilibrium (3) will lose a periodate ligand by exchanging with $2 \mathrm{OH}^{-}$as shown in equilibrium (4).

$$
\left[\mathrm{Ag}\left(\mathrm{H}_{2} \mathrm{IO}_{6}\right)_{2}\right]^{3-}+2 \mathrm{OH}^{-} \rightleftharpoons\left[\mathrm{Ag}\left(\mathrm{H}_{2} \mathrm{IO}_{6}\right)(\mathrm{OH})_{2}\right]^{2-}+\mathrm{H}_{2} \mathrm{IO}_{6}{ }^{3-}
$$

The similar degree of protonation has earlier been postulated by Kirschebaum ${ }^{6}$ and Anil Kumar $e t$. $a l^{15}$. In the present investigation, the orders for various reactants and other species involved in the reaction were determined and the rate of reaction was decreased with increase in $\left[\mathrm{OH}^{-}\right]$. Hence, equilibrium (3) plays an important role in the proposed mechanism. Further, decrease in rate with increase in periodate concentration and unit order each in DPA and $t$-BA can be accommodated in the mechanism as shown in Scheme 1.

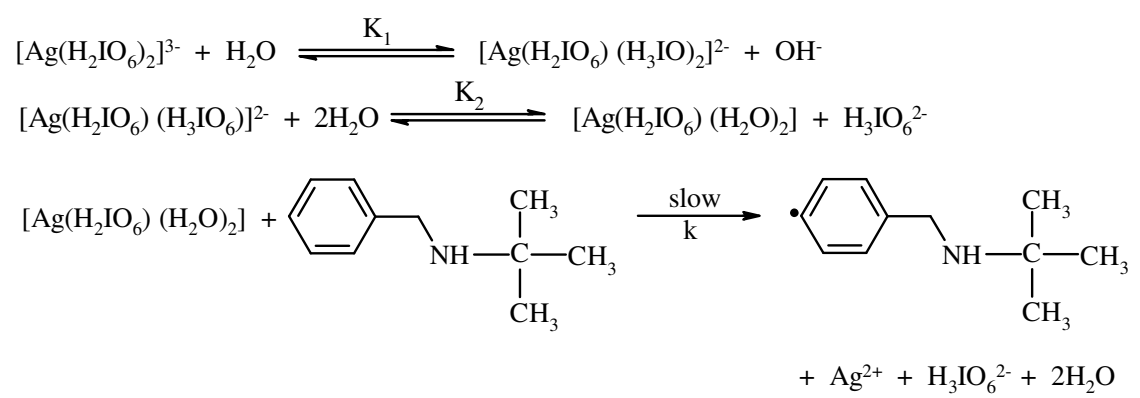<smiles>CC(C)(C)NCc1ccccc1</smiles><smiles></smiles>

\section{Scheme 1}


Step (i) of Scheme 1 implies, the retarding effect of added $\mathrm{OH}^{-}$in the middle concentration range of $\mathrm{OH}^{-}$by converting $\left[\mathrm{Ag}\left(\mathrm{H}_{2} \mathrm{IO}_{6}\right)_{2}\right]^{3-}$ to $\left[\mathrm{Ag}\left(\mathrm{H}_{2} \mathrm{IO}_{6}\right)\left(\mathrm{H}_{3} \mathrm{IO}_{6}\right)\right]^{2-}$. In step (ii), one of the periodate ligands exchange with water molecules to give monoperiodatoargentate(III) (MPA) and free $\mathrm{H}_{3} \mathrm{IO}_{6}^{2-}$ which explains the retarding effect of added periodate on rate of reaction. In slow step (iii), this MPA oxidizes $t$-butylbenzylamine by absorbing proton to lead a free radical generated from $t$-butylbenzylamine. This confirms the experimentally observed fact of polymerization study. The free radical generated in step (iii) further oxidizes to 4-((t-butylamino)methyl)cyclohexa-2,5, dienone in a fast step (iv).

However, Scheme 1 does not account the retarding effect of the added product, $\operatorname{Ag}(\mathrm{I})$. The initial addition of silver(I) might have involved in the complex formation with $t$-BA at imino moiety. This complex would be less reactive compared to the uncomplexed $t$-butylbenzylamine. Such reports are also available in literature ${ }^{16}$. The rate law for the Scheme 1 could be derived as

$$
\begin{aligned}
\text { rate }=\frac{-\mathrm{d}[\mathrm{DPA}]}{\mathrm{dt}} & =\frac{\mathrm{kK}_{1} \mathrm{~K}_{2}[\mathrm{t}-\mathrm{BA}]_{\mathrm{T}}[\mathrm{Ag}(\mathrm{III})]}{\left[\mathrm{OH}^{-}\right]\left[\mathrm{H}_{3} \mathrm{IO}_{6}^{2-}\right]+\mathrm{K}_{1}\left[\mathrm{H}_{3} \mathrm{IO}_{6}^{2-}\right]+\mathrm{K}_{1} \mathrm{~K}_{2}} \\
\mathrm{k}_{\mathrm{obs}} & =\frac{\mathrm{kK}_{1} \mathrm{~K}_{2}[\mathrm{t}-\mathrm{BA}]_{\mathrm{T}}}{\left[\mathrm{OH}^{-}\right]\left[\mathrm{H}_{3} \mathrm{IO}_{6}^{2-}\right]+\mathrm{K}_{1}\left[\mathrm{H}_{3} \mathrm{IO}_{6}^{2-}\right]+\mathrm{K}_{1} \mathrm{~K}_{2}}
\end{aligned}
$$

Eqn. (6) can be rearranged into eqn (7) by omitting ' $\mathrm{T}$ '

$$
\begin{aligned}
\frac{1}{\mathrm{k}_{\mathrm{obs}}}=\frac{\left[\mathrm{OH}^{-}\right]\left[\mathrm{H}_{3} \mathrm{IO}_{6}^{2-}\right]}{\mathrm{kK}_{1} \mathrm{~K}_{2}[\mathrm{t}-\mathrm{BA}]_{\mathrm{T}}}+\frac{\left[\mathrm{H}_{3} \mathrm{IO}_{6}^{2-}\right]}{\mathrm{kK}_{2}[\mathrm{t}-\mathrm{BA}]_{\mathrm{T}}}+\frac{1}{\mathrm{k}[\mathrm{t}-\mathrm{BA}]_{\mathrm{T}}} \\
\frac{[\mathrm{t}-\mathrm{BA}]_{\mathrm{T}}}{\mathrm{k}_{\mathrm{obs}}}=\frac{\left[\mathrm{OH}^{-}\right]\left[\mathrm{H}_{3} \mathrm{IO}_{6}^{2-}\right]}{\mathrm{kK}_{1} \mathrm{~K}_{2}}+\frac{\left[\mathrm{H}_{3} \mathrm{IO}_{6}^{2-}\right]}{\mathrm{kK}_{2}}+\frac{1}{\mathrm{k}}
\end{aligned}
$$

Rate law (6) in the form of (8) is verified by plotting of $[t-\mathrm{BA}] / \mathrm{k}_{\mathrm{obs}}$ versus $\left[\mathrm{H}_{3} \mathrm{IO}_{6}^{2-}\right]$ and $\left[\mathrm{OH}^{-}\right]$, all of which should be linear and are found to be so as shown in Figure 2. From the slopes and intercepts of such plots, the values of $\mathrm{k}=9.85 \mathrm{dm}^{3} \mathrm{~mol}^{-1} \mathrm{~s}^{-1}, \mathrm{~K}_{1}=2.0 \times 10^{-3} \mathrm{~mol} \mathrm{dm}^{-3}$ and $\mathrm{K}_{2}=1.11 \times 10^{-4} \mathrm{~mol} \mathrm{dm}{ }^{-3}$, for $30^{0} \mathrm{C}$ are calculated. Further, these values are used in rate law (6) at different experimental conditions as in Table 1 to regenerate $\mathrm{k}_{\text {obs }}$. The regenerated values are found to be in close agreement with those of experimentally observed values (Table 1). This fortifies the mechanism of oxidation as shown in Scheme 1 and rate law (6).

$$
\left\lceil\mathrm{OH}^{-}\right\rceil \times 10^{3} \mathrm{~mol} \mathrm{dm}^{-3}
$$

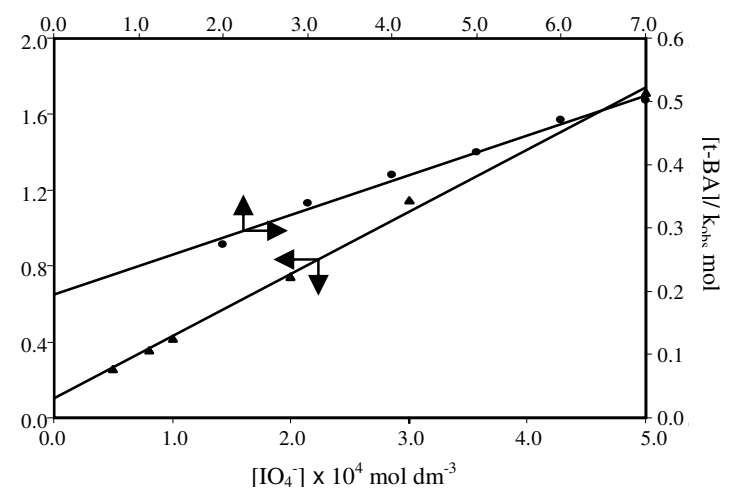

Figure 2. Verification of rate law (8) for the ooxidation of $t$-butylbenzylamine by diperiodatoargentate(III) in aqueous alkaline medium at $30{ }^{\circ} \mathrm{C}$ 
In the experiment it was observed that the rate of reaction is independent upon variation of ionic strength which is in accordance with the interaction between two non-ionic species or at least one among may be non-ionic. The same was found to be so in the slow step(iii) of mechanism of oxidation of $t$-butylbenzylamine in which the non-ionic MPA interacts with nonionic $t$-butylbenzylamine.

The reaction rate was increased with decreasing the dielectric constant of the medium maintained by using $t$-butyl alcohol in water. It is in the expected direction that the non-ionic species are interacting in the lower dielectric constant of the medium more favorable than the polar solvents like water. In the slow step of Scheme 1, both the species are non-ionic hence the rate of oxidation might be more favorable in the lower dielectric constant of the medium. The negligibly small $\Delta \mathrm{S}^{\#}$ value $\left(-18.5 \mathrm{JK}^{-1} \mathrm{~mol}^{-1}\right)$ also supports the involvement of non-ionic species in the rate determining step.

Since the order with respect to oxidant and reductant is one each it is expected that the oxidation follows outer sphere mechanism but it is contradict to the other results of small frequency factor, $\log \mathrm{A}\left(4.5 \mathrm{dm}^{3} \mathrm{~mol}^{-1} \mathrm{~s}^{-1}\right)$ and relatively low value of Ea $\left(41 \mathrm{kJmol}^{-1}\right)$. Hence, it can be concluded that though the order is one each in oxidant and reductant, the small values of Ea and $\log$ A support the inner sphere mechanism.

\section{Conclusion}

$t$-Butylbenzylamine is used as a free base in the synthesis of salbutamol drug. Its oxidation was studied by using DPA in a wide range of $\left[\mathrm{OH}^{-}\right]$. The existence of silver(III) periodate complex in various forms at different $\left[\mathrm{OH}^{-}\right]$are observed. As both oxidant and reductant are two equivalent and complimentary to each other, the reaction may proceed without intervention of free radical. However, the oxidation was proceeded with intervention of free radical. The retarding effect of added product, $\operatorname{Ag}(\mathrm{I})$ is also justified. Ionic strength effect, dielectric constant of the medium and negligibly small value of $\Delta \mathrm{S}^{\#}$ supports the involvement of neutral species.

\section{References}

1. Jenny B, Pharm J., 2007, 279, 404-405.

2. Caruso J F, Signorile J F and Perry A C, Med Sci Sports Exerc., 1995, 27(11), 1471-1476.

3. Ilyas M, Malik M A, Al-Mossalamy E H and Khan Z, J Dispersion Sci Technol., 2010, 31(1), 50-56.

4. Jaiswal P K and Yadav K L, Talanta, 1970, 17(3), 236-238.

5. Kirschenbaum L J, Ambrus J H and Atkinson G, Inorg Chem., 1973, 12, 2832-2837.

6. Kirschenbaum L J, J Inorg Nucl Chem., 1976, 38, 881-884.

7. Jose T P, Angadi M A, Salunke M S and Tuwar S M, Main Group Chem., 2008, 7, 109-122.

8. Kumar A, Vaishali and Ramamurthy P, J Chem Soc Perkin Trans., 2001, 2, 1174-1179.

9. David C T, David H, David J, Press J C, Lunts L C H, Alexander C R and Paul T, J Med Chem., 1970, 13, 674-680.

10. Cohen G I and Atkinson G, Inorg Chem., 1964, 3, 1741-1743.

11. Jeffery G H, Bassett J, Mendham J and Denny R C, Vogel's Textbook of Quantitative Chemical Analysis, Fifth Ed., Longamons Singpore, Publishers Pte. Ltd. Singapore, 1996, p. 467 and p.391.

12. Lide D R, CRC Hand Book of Chemistry and Physics, $73^{\text {rd }}$ Ed., CRC Press, London, $1992, \mathrm{p} 8$.

13. Kolthoff I M, Meehan E J and Carr E M, J Am Chem Soc., 1953, 75, 1439-1441.

14. Reddy K B, Sethuram B and Navaneeth Rao T, Z Phys Chem., 1987, 268, 706-710.

15. Kumar A, Kumar P and Ramamurthy P, Polyhedron, 1999, 18(6), 773-780.

16. Angadi M and Tuwar S M, J Solution Chem., 2010, 39(2), 165-177. 


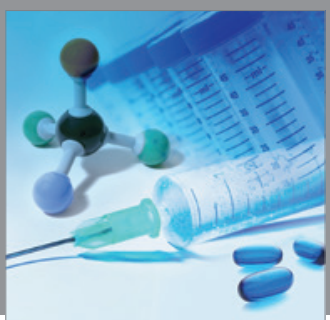

International Journal of

Medicinal Chemistry

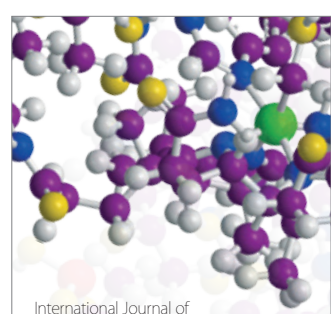

Carbohydrate Chemistry

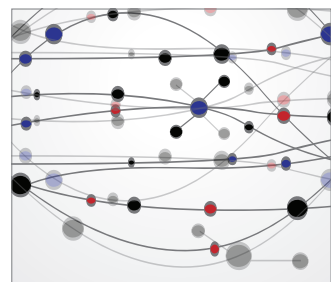

The Scientific World Journal
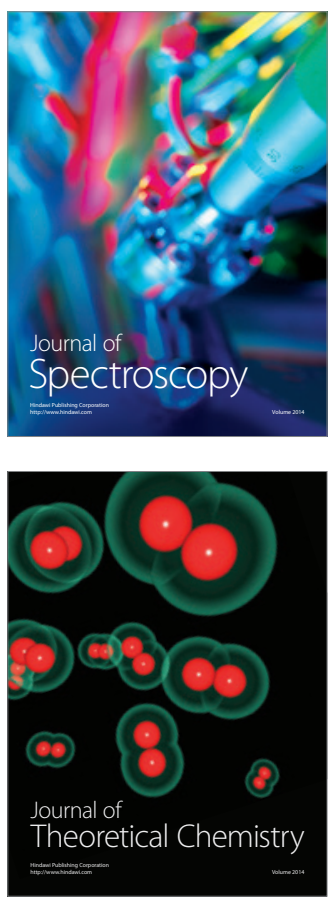


Submit your manuscripts at

http://www.hindawi.com

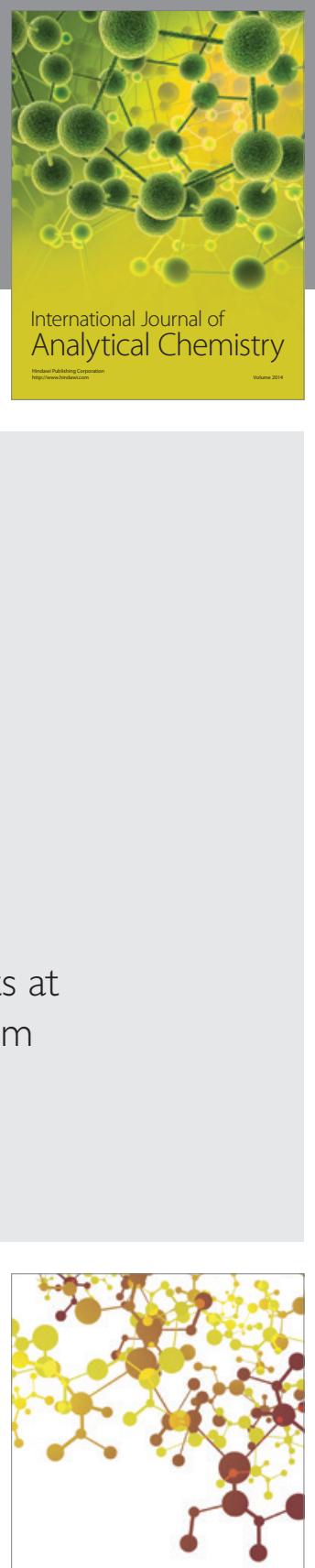

Journal of

Applied Chemistry
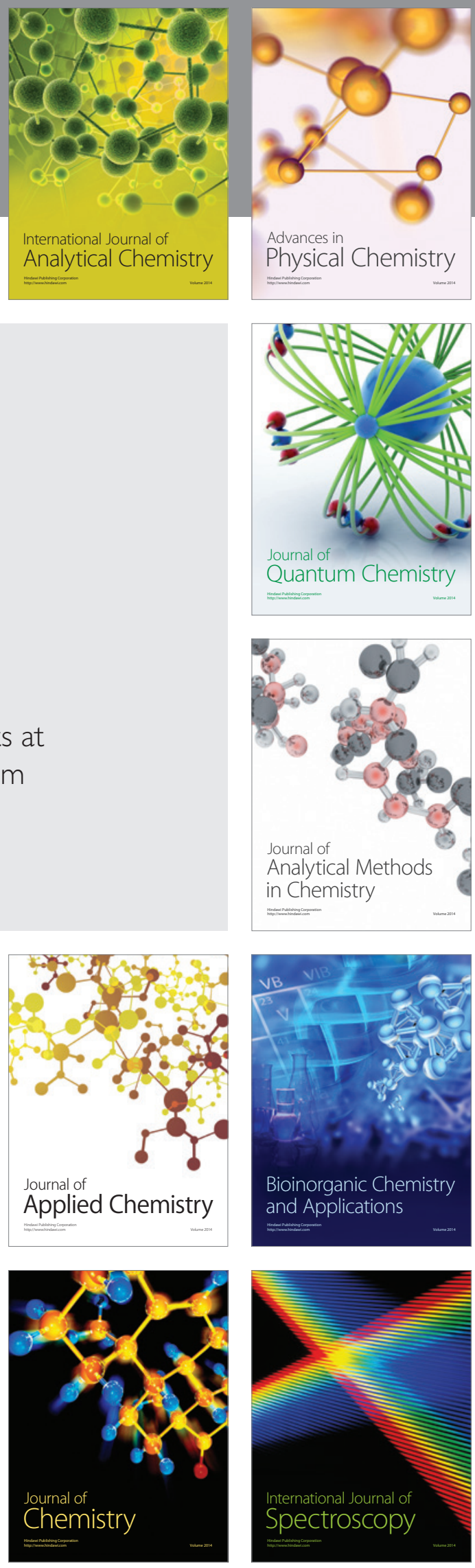